\section{Brazilian Journal \\ of Chemical \\ Engineering}

ISSN 0104-6632

Printed in Brazil

www.abeq.org.br/bjche

\title{
APPROACHES TO PREPARE TFC POLYAMIDE MEMBRANES BY COATING DIAMINE DURING, AND/OR POST FORMATION OF ASYMMETRIC MEMBRANES AND THEIR PERFORMANCES
}

\author{
R. N. Joshi, K. Singh and A. Bhattacharya* \\ Reverse Osmosis Discipline, Central Salt and Marine Chemicals Research Institute, \\ (Council of Scientific and Industrial Research), Phone: + 91-278-2567760x-761, Fax: + 91-278-2567562, \\ G. B. Marg, Bhavnagar, 364002, Gujarat, Índia. \\ E-mail: bhattacharyaamit1@rediffmail.com
}

(Submitted: November 23, 2010 ; Revised: January 25, 2011 ; Accepted: March 7, 2011)

\begin{abstract}
Thin film composite membranes were prepared by using1,3-phenylene diamine in the gelation bath as well as in coating conditions. The cross-sectional view of the membranes shows different patterns for membranes prepared in a water-bath (Mem- I) and a diamine-containing water bath (Mem-II). The thin film composite membranes prepared using a diamine bath and coating (Mem-III) had improved salt rejecting ability but low volume flux. The performances of the salt rejection follows the order $\mathrm{Na}_{2} \mathrm{SO}_{4}>\mathrm{NaCl}>\mathrm{MgSO}_{4}>\mathrm{MgCl}_{2}$, as expected. The salt separation performances of the membranes made with higher concentration of 1,3 phenylene diamine follow the order Mem-IIIb $>$ Mem-I $>$ Mem-IIb. For membranes made with low concentration of 1,3-phenylene diamine, the salt separation follows the same trend, (Mem-IIIa $>$ Mem-IIa).

Keywords: Membrane; Thin film composite; 1,3-phenylene diamine; Gelation bath; Salt rejection.
\end{abstract}

\section{INTRODUCTION}

The beginning of polymer membrane science and technology occurred with the success of Yuster in 1958 (Yuster et al., 1958) with cellulose acetate. Cadotte's significant work was with thin film composite membranes (Cadotte, 1977; Cadotte et al., 1981, Petersen, 1993) based on preparation of asymmetric polysulfone membranes and the coating of crosslinked polyamide via interfacial polymerization on them (Morgan, 1965). The crosslinked polyamide formation was carried out using 1,3-phenylene diamine and trimesoyl chloride.

The preparation of asymmetric membranes can be done by different methods. Wet phase inversion is frequently employed as it is simple and of low cost. In the phase inversion technique, there is an interplay between the polymer and its solvent and non-solvent.
The asymmetric character is generated because of the difference in diffusion exchange between the top phase and the bottom phase of the membrane. It helps the diffusion and pore-controlled transport through the membrane. Moreover, it is also helpful in interfacial polymerization to form a thin salt rejecting polyamide layer. Generally the interfacial polymerization reaction is between amine and acyl halide functionalities. The reaction occurs at the junction of the two interfaces (viz., water and organic). Although it is termed 'interfacial', the reaction takes place in the organic phase because the highly unfavorable partition coefficient of the acid chloride limits its availability in the aqueous phase (Morgan, 1965).

Membrane preparation is an art. The role of additives in the gelation bath during the preparation of membranes by the wet phase inversion technique

*To whom correspondence should be addressed 
has been reported. (Vandezande, 2008). The conformation of the membranes is varied by adding higher molecular weight alcohols (Boussu et al., 2006) (Deshmukh and Li, 1998) (Leblanc et al., 2001), the same solvents used for polymer solution (Bottino et al., 1985) (Konagaya, 2001), or macromolecular additives (Javiya et al., 2008). In the present study, we prepare thin film composite membranes by preparing asymmetric polyether sulfone membranes in a water gelation bath, mixed with 1,3-phenylene diamine with interfacial polymerization in the usual manner. The role of additive in the gelation bath in terms of performances of the membranes for salt separation is compared with that of the usual thin film composite membranes prepared in the laboratory.

\section{EXPERIMENTAL}

\section{Materials}

Polyether sulfone (Gardah Chemicals, India) and $\mathrm{N}, \mathrm{N}$-dimethyl formamide (Qualigen, India) were used for the preparation of the membranes. The inherent viscosity of polyether sulfone was $1.27 \mathrm{dL} / \mathrm{g}$ in $\mathrm{N}$-methyl pyrrolidone. 1,3-phenylene diamine (Arti Industries, India) and trimesoyl chloride (Lancaster, USA) were used for interfacial polymerization to form the polyamide. $\mathrm{Na}_{2} \mathrm{SO}_{4}$ (Molychem, India), $\mathrm{NaCl}$, $\mathrm{MgSO}_{4}$ and $\mathrm{MgCl}_{2}$ (Qualigens, India) were used for the salt separation study. In all the experiments, reverse osmosis treated water was used.

\section{Methods}

\section{Preparation of Asymmetric Polyether Sulfone Membranes}

Polyethersulfone solution $(16 \% \quad \mathrm{w} / \mathrm{w})$ was prepared in $\mathrm{N}, \mathrm{N}$-dimethyl formamide by slow heating and stirring. The solution was cast on non-woven polyester fabric pasted on a glass plate. The cast polyether sulfone was immersed at once $(>10 \mathrm{sec})$ in the gelation bath (nonsolvent-water). In another approach, the cast polyether sulfone was immediately immersed $(>10 \mathrm{sec})$ into the water gelation bath, mixed with 1,3-phenylene diamine $(0.1$ and $0.2 \%)$. The gelation bath temperature was kept at $27^{\circ} \mathrm{C}$. The excess aqueous solution was removed from the top of the membrane by suspending it for $10 \mathrm{~min}$.

\section{Preparation of Thin Film Composite Membranes}

The asymmetric polyether sulfone was placed on a glass tray. The interfacial polymerization of 1,3-phenylene diamine and trimesoyl chloride was done at the water-hexane interface. The asymmetric polyether sulfone prepared in the diamine gelation bath was also treated in the same manner. The same membrane was also treated with trimesoyl chloride alone. The details of the membrane preparation are given in Table 1.

\section{Techniques}

A laboratory-made pressure cell was used for testing the permeability of the salt solutions. The cross-flow filtration mode was used and salt rejection measurements were done based on conductivity data by using a Eutech Instruments, CON 510 conductivity-TDS meter (Singapore). The experimental set-up used for cross-flow filtration of the solution is shown in Figure 1. The applied crossflow filtration pressure was set at $1.4 \mathrm{MPa}$ and $25^{\circ} \mathrm{C}$ for all salt rejection experiments. The pressure was kept at $6.2 \mathrm{MPa}$ for the sea water filtration because of its higher osmotic pressure. The cross-sectional examination of all the membranes was carried by scanning electron microscopy (Leo, 1430UP, Oxford Instruments).

Table 1: Membrane Preparation conditions

\begin{tabular}{|l|l|c|l|l|}
\hline Membrane & \multicolumn{1}{|c|}{ Gelation bath composition } & \multicolumn{2}{|c|}{ Conditions } & \\
\hline & & $\begin{array}{l}\text { Trimesoyl chloride } \\
(2 \% \text { in water) } \\
\text { (Dipping time) }\end{array}$ & $\begin{array}{l}\text { (0.1\% in hexane) } \\
\text { (Dipping time) }\end{array}$ & Drying time: 1 min \\
Mem-I & water & $5 \mathrm{~min}$ & 2 min & Curing Temp: $80-90^{\circ} \mathrm{C}$ \\
Mem-IIa & Water $+1,3$-phenylenediamine $(0.1 \%)$ & - & & \\
Mem-IIb & Water $+1,3$-phenylenediamine $(0.2 \%)$ & - & & \\
Mem-IIIa & Water $+1,3$-phenylenediamine $(0.1 \%)$ & 5 min & & \\
Mem-IIIb & Water $+1,3$-phenylenediamine $(0.2 \%)$ & $5 \mathrm{~min}$ & & \\
\hline
\end{tabular}




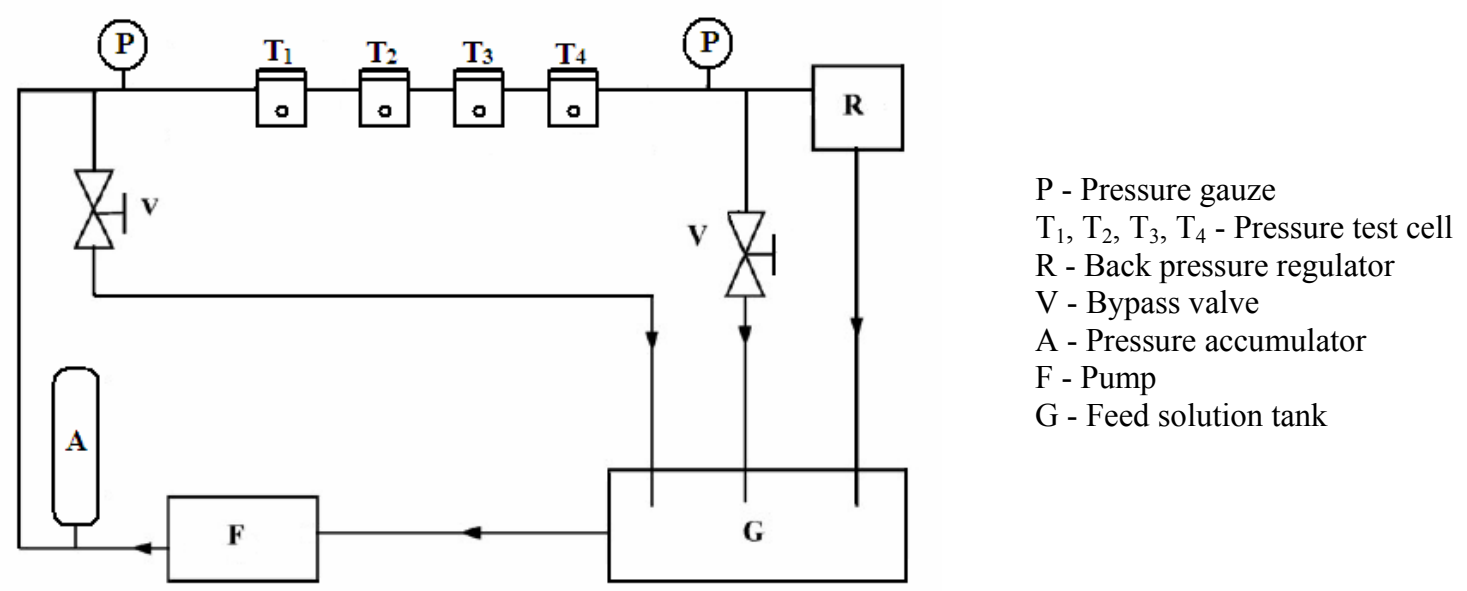

Figure 1: Schematic diagram of the cross-flow filtration mode

\section{RESULTS AND DISCUSSION}

The phase inversion technique was employed for membrane preparation. In this technique, a ternary mixture (polymer: polyethersulfone, solvent: $\mathrm{N}, \mathrm{N}$-dimethyl formamide, and coagulant: water) is formed. Upon introduction of the third component water, i.e., a nonsolvent for polyethersulfone, the mixture phase separates and results in 'polymer-rich' and 'polymer-lean' phases (Kim et al., 1997). Changes in the composition of the polymer-solventnonsolvent system produced by mass transfer of the nonsolvent into the casting solution and of solvent into the coagulation bath during the wet phase inversion are the mechanisms of the membrane preparation. The polymer-rich phase is predominantly the polymeric membrane and precipitates out of the mixture as a thin porous solid film. It forms as soon as the cast membrane is in contact with the coagulant water. The polymer-lean phase forms a diffusion exchange layer between solvent and nonsolvent from the bottom of the thin dense skin layer.

The changes in the composition can be described by four steps, viz., solidification, nucleation and growth of the polymer-lean phase, spinodal demixing, and nucleation and growth of the polymerrich phase. The initial solidification is apparently the same for all the membranes, but other steps relate to the diffusional exchange of the nonsolvent-solvent. The presence of 1,3-phenylene diamine in the gelation bath results in slow diffusion exchange and Mem-II and Mem-III forms as a result. The visual appearance shows that the phase inversion mechanism is delayed for the two membranes. The decrease in weight $\left(\sim 4.4-7.2 \times 10^{-4} \mathrm{~g} / \mathrm{cm}^{2}\right)$ suggests that the polymer- lean phase portion is comparatively higher than for polyether sulfone prepared in a water gelation bath only, though there is diamine attachment.

The interfacial polymerization is the key reaction to form the thin polyamide layer. It occurs between 1,3-phenylene diamine (in water) and trimesoyl chloride (in hexane) (Figure 2). The crosslinked network forms with the interchain - $\mathrm{CONH}$ - linkage between the aromatic rings. The asymmetric character of the polyether sulfone membrane helps the attachment of the crosslinked network on the support matrix. The interfacial polymerization was done after the preparation of the asymmetric polyether sulfone membrane for Mem-I. Table 1 features the different pathways used to prepare the thin film composite membranes. The 1,3-phenylene diamine is adsorbed/absorbed to the polyether sulfone matrix from the non-solvent (to polymer) gelation bath for Mem-II. Interfacial polymerization with trimesoyl chloride occurred with the adsorbed 1,3-phenylene diamine. In the case of Mem-III, the asymmetric membrane was prepared in the 1,3-phenylene diamine mixed gelation bath similar to Memb-II and then interfacial polymerization was done as in Mem-I. The feasibility of the formation of the polyamide layer is poor with the excess water content in it because the interfacial reaction is in organic phase. Figure 3 presents volume and solute fluxes for all the thin film composite membranes. The higher flux was for the membranes (Mem-II) (Table 1 and Figure 3) in which low concentrations of 1,3-phenylene diamine were used in the gelation bath. 


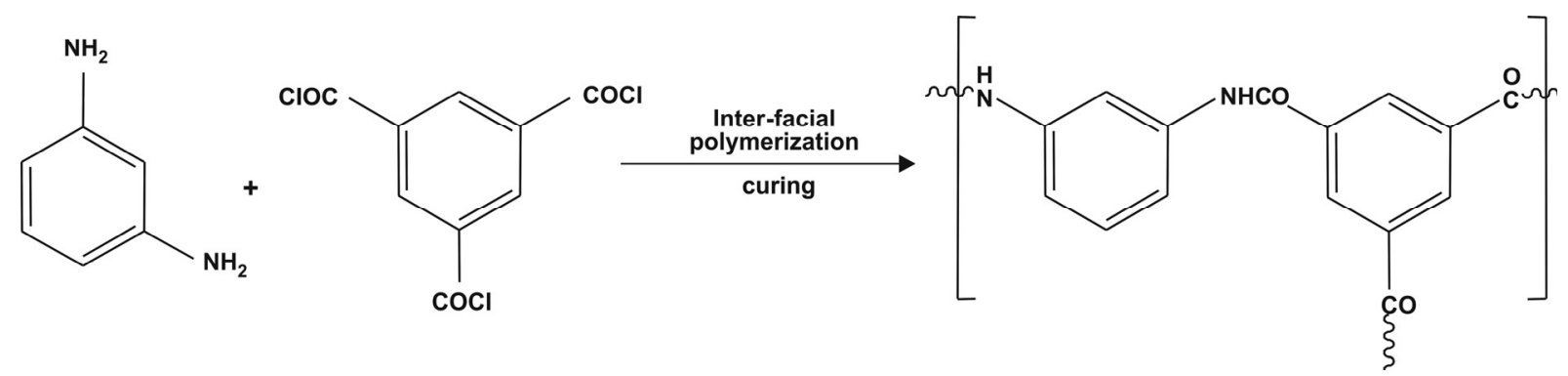

Figure 2: Interfacial polymerization reaction of 1,3-phenylene diamine and 1,3,5-trimesoyl chloride.
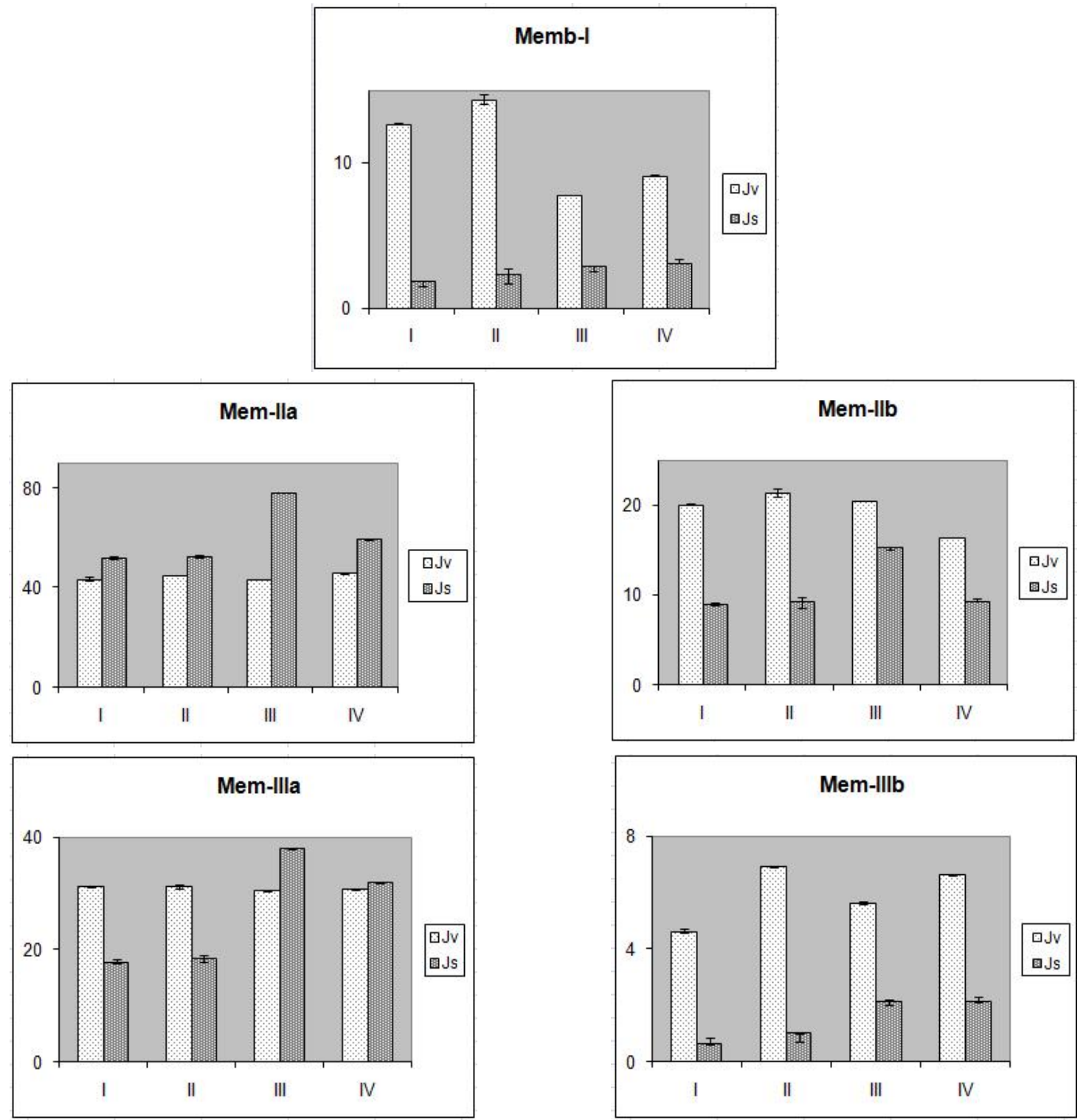

Figure 3: Volume $\mathrm{J}_{\mathrm{v}},\left(1 \mathrm{~m}^{-2} \mathrm{~h}^{-1}\right)$ and solute flux $\mathrm{J}_{\mathrm{s}},\left(\mathrm{gmm}^{-2} \mathrm{~h}^{1}\right)$ of all the membranes for different salts (I. $\mathrm{Na}_{2} \mathrm{SO}_{4}$, II. $\mathrm{NaCl}$, III. $\mathrm{MgSO}_{4}$, IV. $\mathrm{MgCl}_{2}$ ). (*average of four measurements) 
The cross-sectional morphology of the membranes is shown in Figure 4. The cross-sectional view of the membranes reflects the asymmetric nature along the axis perpendicular to the plane of the film. The polymer-rich phase is at the top where as channels and macrovoids are beneath the top layer. The polymer-rich phase channels at the top are much wider for the membranes prepared in the water bath compare to membranes prepared in 1,3-phenylene diamine mixed bath because of its slow diffusion. The affinity of polyether sulfone for the diamine is another factor that may also control the conformation. The macrovoids are comparatively broader and with no geometric form for Memb-I.
But, in the case of Memb-II, the macrovoids are more or less straight and finger-like. The nonmacrovoid and finger-like part of the membranes consists of a well-developed cellular structure in the lower part of the membrane. The polymer- rich phase is distributed along the depth of the membrane for $11-16 \mu \mathrm{m}$ from the top for the membrane prepared in the water bath compared to $8-9 \mu \mathrm{m}$ in the 1,3-phenylene diamine aqueous bath. In all the cases, polyamide is supported in the top morphological view of the membranes. The appearance of the top view is different with the use of 1,3-phenylene diamine. It is more prominent in Mem-III compared to Mem-II and Mem-I. (Figure 5).

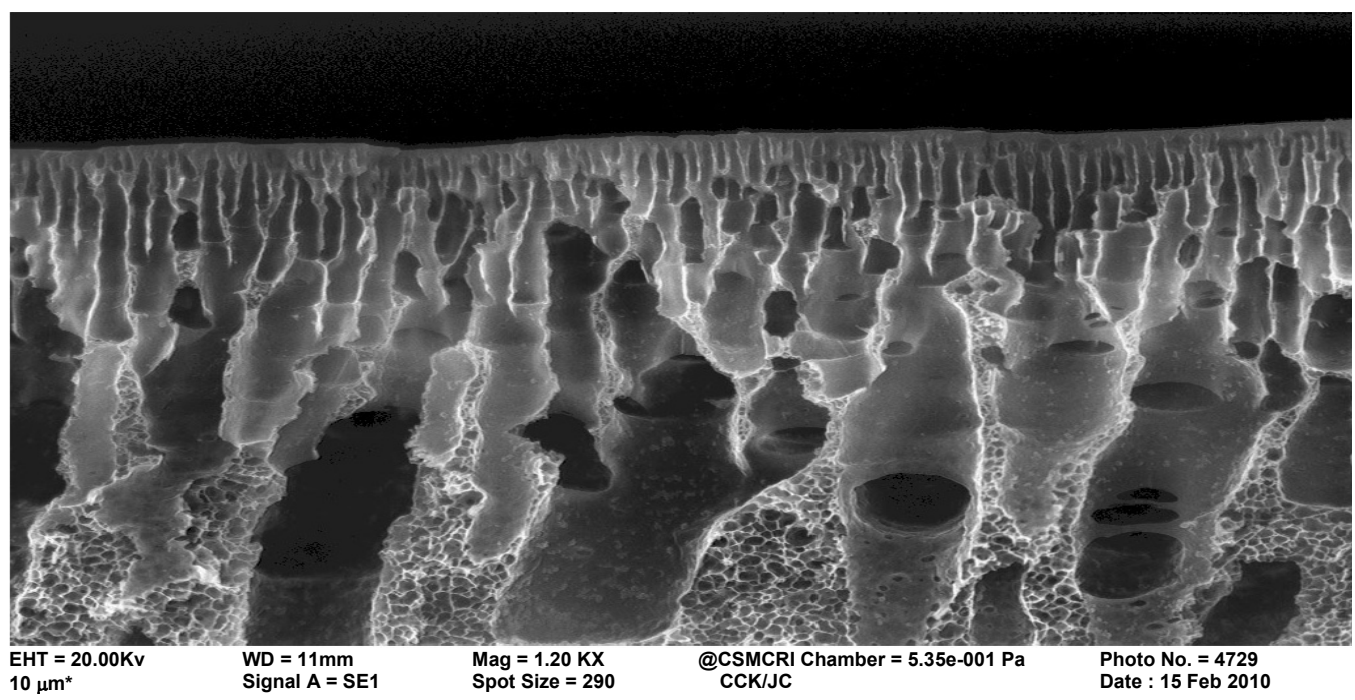

(a)

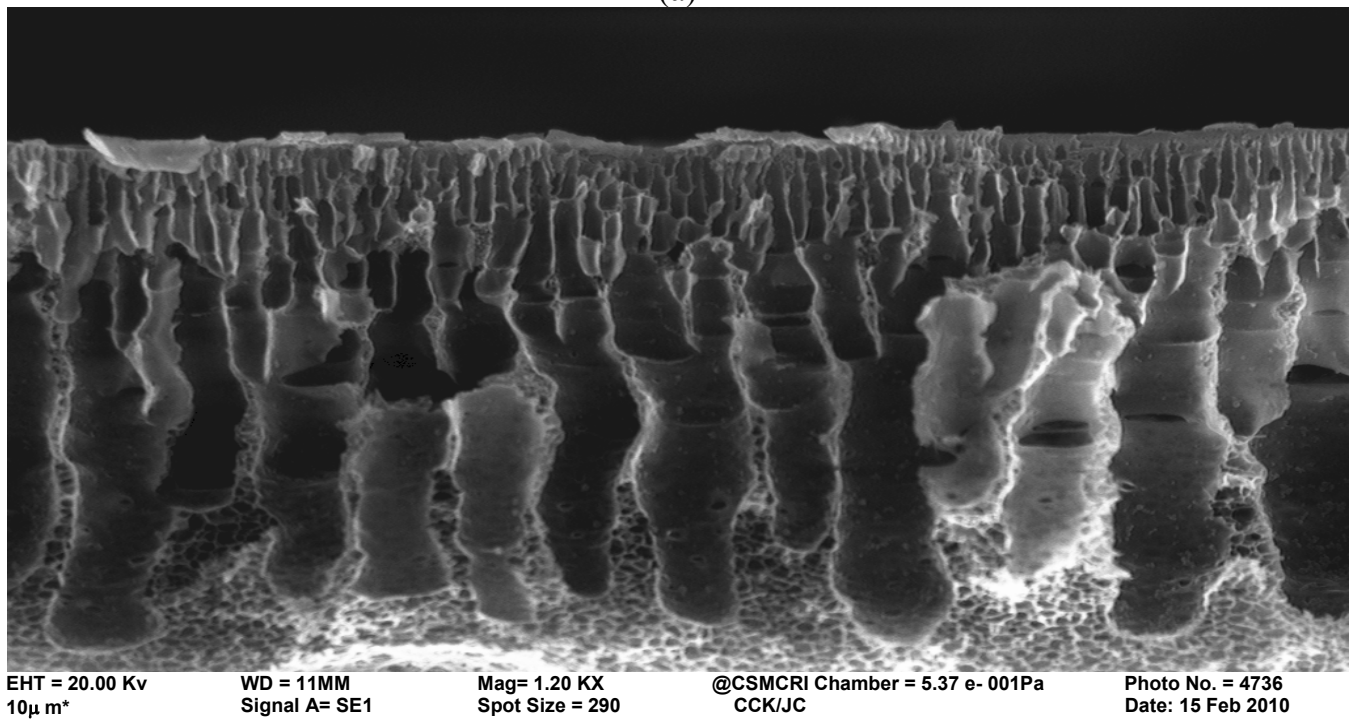

(b)

Figure 4: Cross-section morphology of asymmetric polyether membranes prepared (a) in water and (b) in aqueous solution of 1,3-phenylene diamine. 


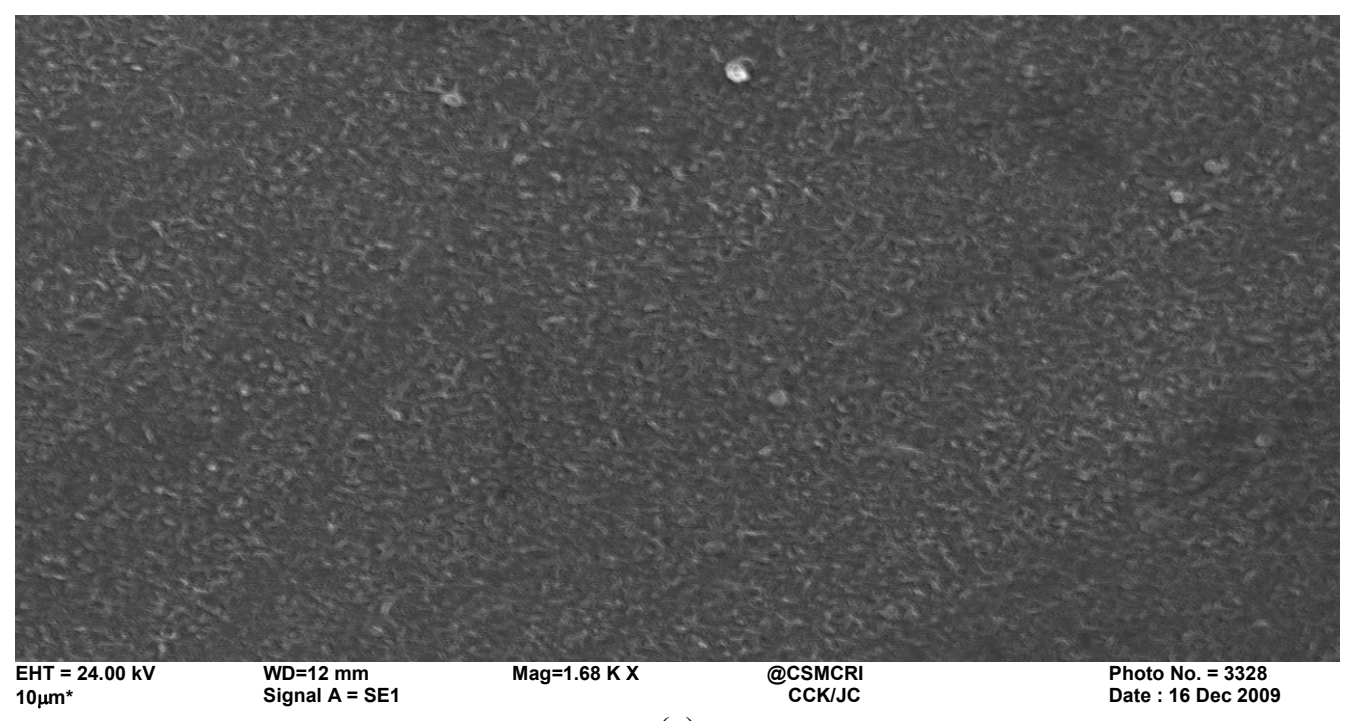

(a)

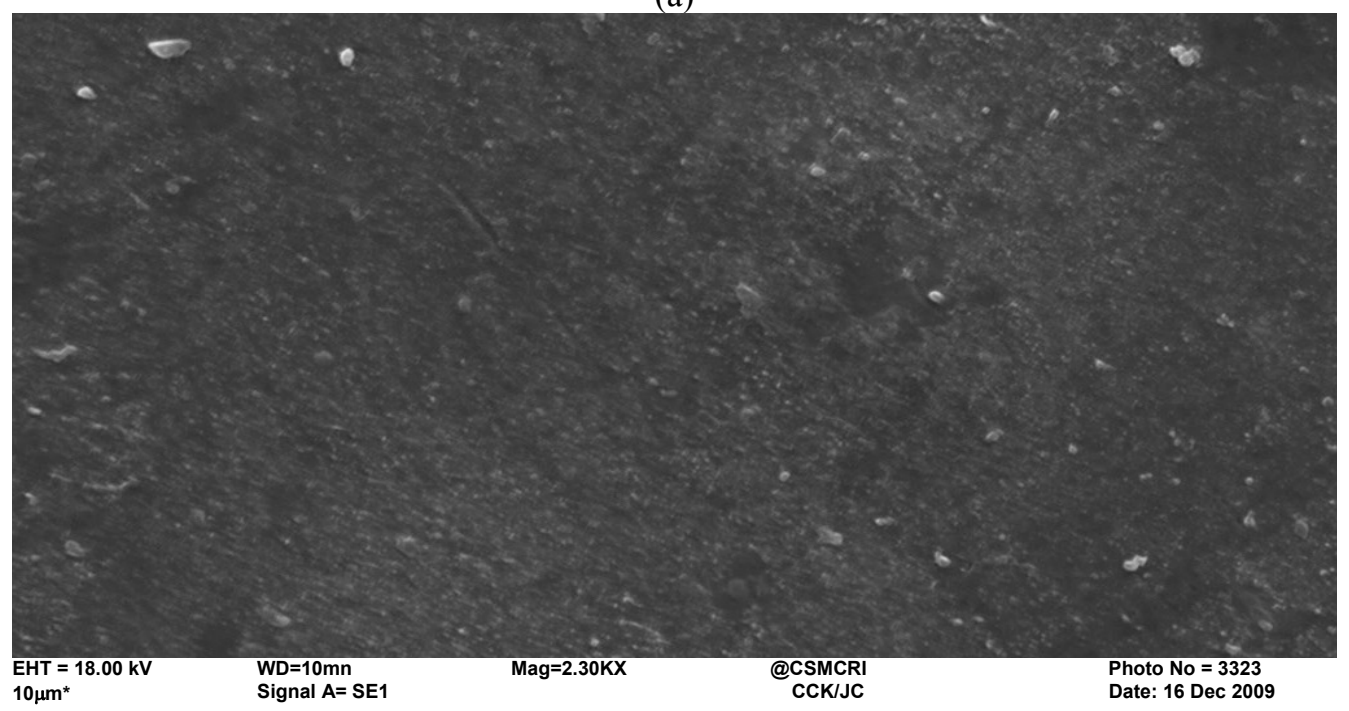

(b)

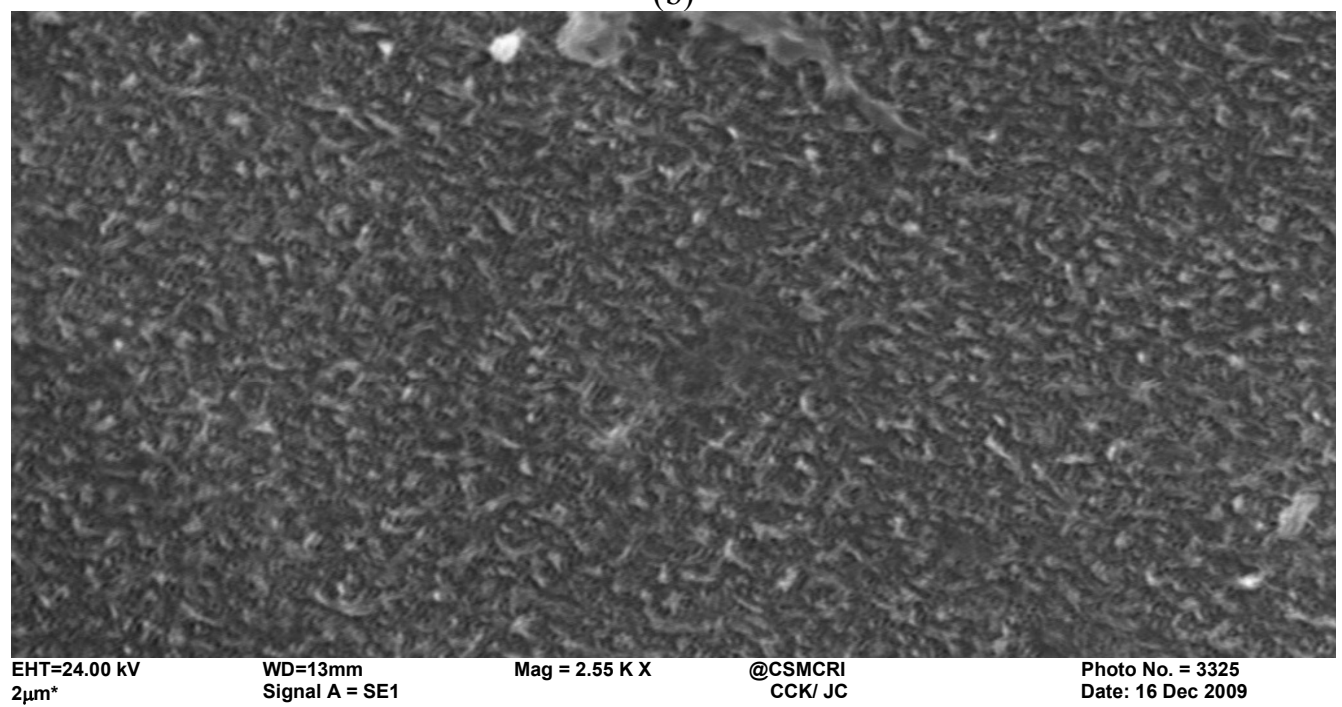

(c)

Figure 5: Top view of thin film composite membranes (a) Mem-I, (b) Mem-IIb and (c) Mem-IIIb). 
Figure 6 shows the salt rejection performance upon changing the preparative technique of the thin film composite membrane. The transport phenomena of salt through a thin film composite membrane can be explained by different theories (preferential sorption, electrical) (Bhattacharya et al., 2004). In the preferential sorption theory, water preferentially sorbs at the membrane solution interface and then moves through the capillaries of the membrane by viscous flow in which the flux is directly proportional to the effective pressure. In the NernstPlanck theory, the movement of ions through membrane pores is by convection, diffusion and the electric potential gradient. From a chemical perspective, the formation of $-\mathrm{COOH}$ functionality in the cross-linked polyamide is the key to repel the salt, as well as polar compounds (Yogesh et al., 2008). It is seen from the figure that the salt rejection performance follows the order Mem-IIIb > Mem-I > Mem-IIb. This may be due to better attachment (adsorption/absorption) of 1,3-phenylene diamine in Mem-III as it occurs twice, i.e., in the gelation bath and in coating. The attachment of 1,3-phenylene diamine on Mem-I follows this order, as the efficiency in coating is better than in the gelation bath.
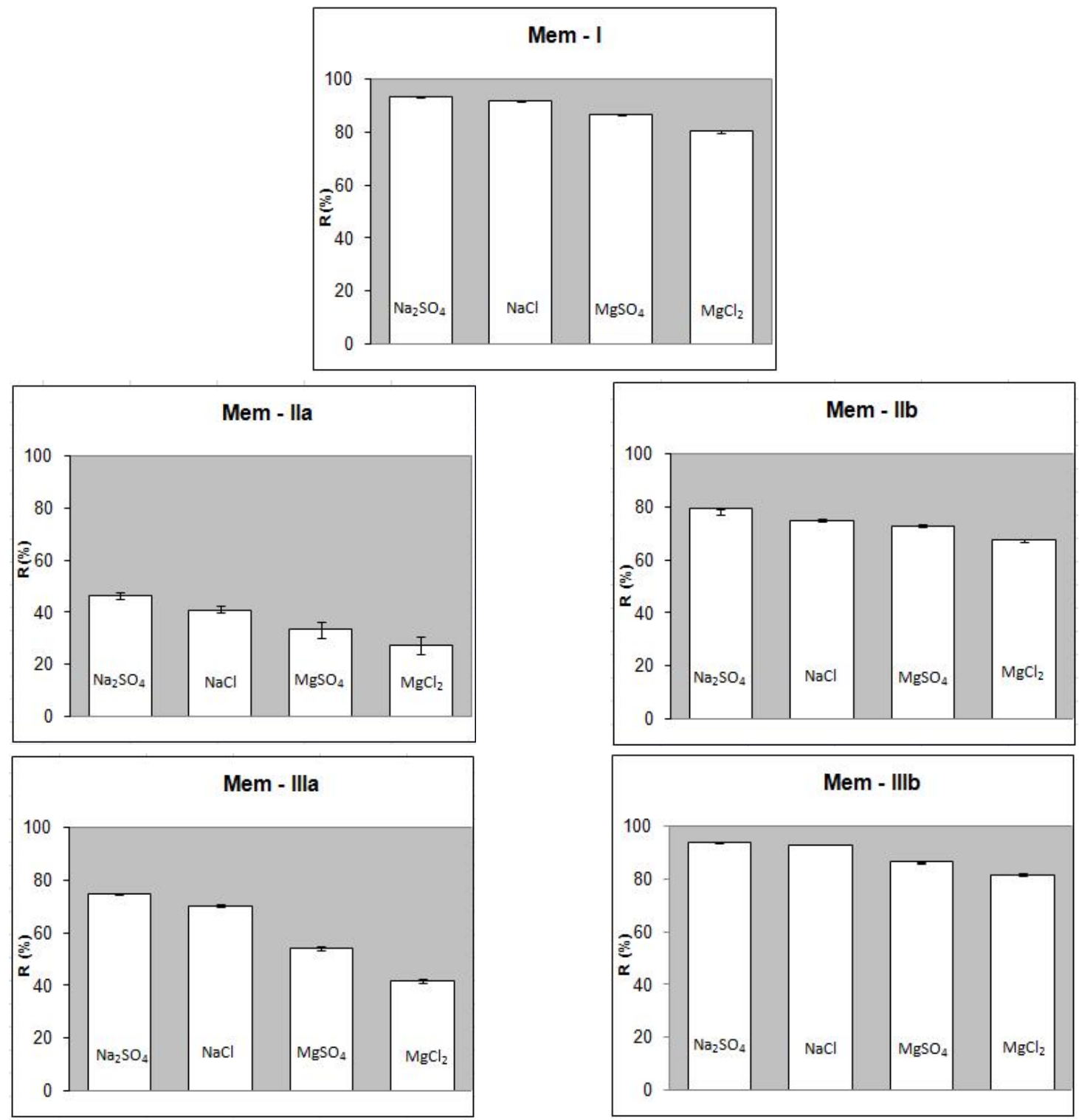

Figure 6: Rejection performances of different membranes for different salts $\left(\mathrm{Na}_{2} \mathrm{SO}_{4}, \mathrm{NaCl}\right.$, $\mathrm{MgSO} 4$, and $\mathrm{MgCl}_{2}$ ). (*average of four measurements) 
The salt rejection follows the order $\mathrm{Na}_{2} \mathrm{SO}_{4}>\mathrm{NaCl}$ $>\mathrm{MgSO}_{4}>\mathrm{MgCl}_{2}$. This sequence is predictable from Donnan characteristics (Bhattacharya and Ghosh, 2004). The valence factor plays a role in the case of the first two. The membranes have higher rejections for high-valence anions and low-valence cations than low-valence anions and high-valence cations, as shown by Dai et al. (2002) The size factor between $\mathrm{Na}^{+}$and $\mathrm{Mg}^{2+}\left(\mathrm{Na}^{+}>\mathrm{Mg}^{2+}\right)$ also supports the order in the case of $\mathrm{NaCl}$ and $\mathrm{MgCl}_{2}$. To compare the rejection of $\mathrm{NaCl}$ and $\mathrm{MgSO}_{4}$, an explanation is given by $\mathrm{He}$ et al. (2008) and Mino et al. (2007); $\mathrm{Mg}^{2+}$ has more adsorption ability, which would decrease the effective surface charge of the membranes and thus the order. The volume $\left(\mathrm{J}_{\mathrm{v}}\right)$ and solute $\left(\mathrm{J}_{\mathrm{s}}\right)$ fluxes of the respective salts are collected in Figure 7. The $J_{v}$ and $J_{s}$ values follow the order Mem-IIa $>$ Mem-IIIa $>$ Mem-IIb $>$ Mem-I $>$ Mem- IIIb. Membrane IIIb possesses the lowest solute and volume flux in terms of $\mathrm{Na}_{2} \mathrm{SO}_{4}$.

The rejection performance for seawater was tested for Mem-I, Mem-IIb and Mem-IIIb. It shows the trend Mem-IIIb > Mem-I > Mem-IIb for the membranes as for $\mathrm{NaCl}$. The volume flux $\left(\mathrm{J}_{\mathrm{v}}\right)$ also showed the similar trend Mem-IIb > Mem-I > Mem-IIIb. The data are given in Figure 7.

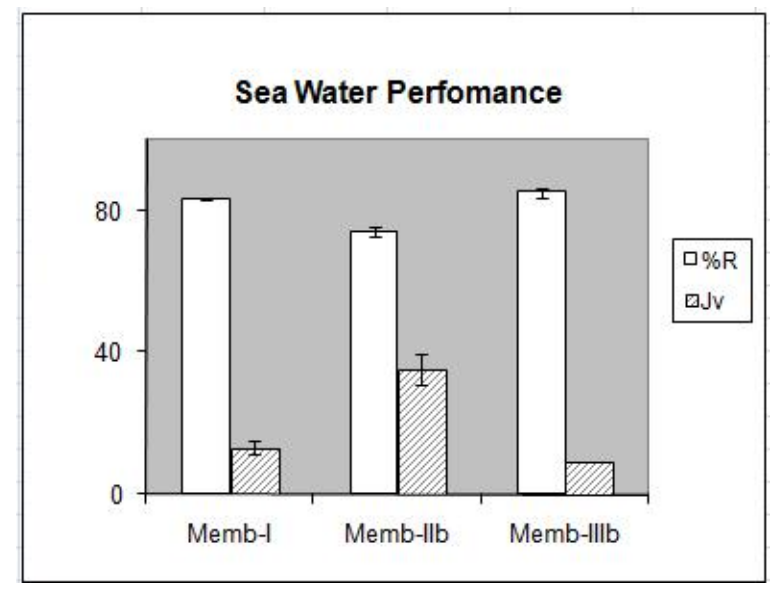

Figure 7: Separation performances $\left(\mathrm{R} \%, \mathrm{~J}_{\mathrm{v}},\left(\mathrm{L} \mathrm{m}^{-2} \mathrm{~h}^{-1}\right)\right)$ of membranes for seawater (*average of four measurements)

\section{CONCLUSIONS}

Different approaches are used to prepare thin film polyamide composite membranes. The membranes were prepared with 1,3-phenylene diamine in the gelation bath. The diamine was also used in the gelation as well as in coating. The membranes prepared from a combination of both gelation and coating (Mem-III) show more salt rejection with lower $\mathbf{J}_{\mathrm{V}}$ with respect to the membranes prepared with the diamine under coating conditions. The cross-sectional morphology of the membranes shows the different nature of the thin dense layer and the macrovoids. The salt rejection follows the order $\mathrm{Na}_{2} \mathrm{SO}_{4}>\mathrm{NaCl}>\mathrm{MgSO}_{4}>\mathrm{MgCl}_{2}$. The salt separation performances for salt and seawater follow the order Mem-IIIb > Mem-I > Mem-IIb. The performance of the membranes can be tailor-made with the use of 1,3-phenylene diamine. However, the salt separation of Mem-IIIa and Mem-IIb follows different trends, because of their concentration.

\section{ACKNOWLEDGEMENT}

Council of Scientific and Industrial Research, (CSIR), India.

\section{REFERENCES}

Bhattacharya, A., Ghosh, P., Nanofiltration and Reverse Osmosis membrane: Theory and application in separation of electrolytes. Rev. Chem. Eng., 20, (1-2), 111 (2004).

Boussu, K., Vandecasteele, C., Van der Bruggen, B., Study of the characteristics and the performance of self-made nanoporous polyethersulfone membranes. Polymer 47, 3464 (2006).

Bottino, A., Caparnelli, G., Munari, S., Effect of coagulation medium on properties of sulfonated polyvinylidine fluoride membranes. J. Appl. Polym. Sci., 30, 3009 (1985).

Cadotte, J. E., Reverse osmosis membrane. U.S. Patent 4,039,440, August 2 (1977).

Cadotte, J. E., Peterson, R. J., in: A. F. Turbak, (Ed.), Thin film Composite Reverse Osmosis Membranes: Origin, Development, and recent Advances in: Synthetic Membranes. Vol. I, Desalination, Am. Chem. Soc., Washington, DC (1981).

Dai, Y., Jian, X., Zhang, S., Guiver, M. D., Thin film composite (TFC) membranes with improved thermal stability from sulfonated poly(phthalazinone ether sulfone ketone) (SPPSEK). J. Memb. Sci., 207, 189 (2002).

Deshmukh, S. P., Li, K., Effect of ethanol composition in water coagulation bath on morphology of PVDF hollow fibre membranes. J. Membr. Sci., 150, 75 (1998).

He, T., Frank, M., Mulder, M. H. V., Wessling, M., Preparation and characterization of nanofiltration 
membranes by coating polyethersulfone hollow fibers with sulfonated poly(ether ether ketone) (SPEEK). J. Memb. Sci., 307, 62 (2008).

Javiya, S., Yogesh, Gupta S., Singh. K., Bhattacharya, A., Porometry Studies of the Polysulfone Membranes on addition of Poly (ethylene Glycol) in Gelation Bath During Preparation. J. Mex. Chem. Soc., 52, (2), 140 (2008).

Kim, J. Y., Lee, H K., Baik,, K. J., Kim, S. C., Liquid-liquid phase separation in polysulfone/ solvent/water systems. J. Appl. Polym. Sci., 65, 2643 (1997).

Konagaya, S., Kuzumoto, H., Watanabe, O., Reverse osmosis performance and chlorine resistance of new ternary aromatic copolyamides comprising 3,3'diaminodiphenylsulfone and a comonomer with a carboxyl group. J. Appl. Polym. Sci., 80, 505 (2001).

Leblanc, N., Le Cerf, D., Chappey, C., Langeyin, D., Me'tayer, M., Muller, G., Influence of solvent and non-solvent on polyimide asymmetric membranes formation in relation to gas permeation. Sep. Purif. Technol., 22-23, 277 (2001).
Mino, J., Chen, G., Li, L., Dong, S., Formation and Characterization of carboxymethyl Cellulose Sodium (CMC-Na)/ Poly (vinyldiene fluoride) (PVDF) Composite Nanofiltration Membranes. Sep. Sci. Tech., 42, 3085 (2007).

Morgan, P. W., Condensation Polymers: By interfacial and solution methods. Interscience Publishers, NY (1965).

Petersen, R. J., Composite reverse osmosis and nanofiltration membranes. J. Memb. Sci., 83, 81 (1993).

Vandezande, P., Gevers, L. E. M., Vankelecom, I. F. J., Sovlent resistant nanofiltration: separating on a molecular level. Chem. Soc. Rev., 37, 365 (2008).

Yogesh, Popat, K. M., Ganguly, B., Brahmbhatt, H., Bhattacharya, A., Studies on the separation performances of chlorophenol compounds from water by Thin film composite membranes, Macromol Res, 16, (7), 590 (2008).

Yuster, S. T., Sourirajan, S., Bernstein, K., Sea water Demineralization by the 'Surface Skimming' Process. University of California (UCLA), Dept, of Engineering, March, Report No, 58-26 (1958). 